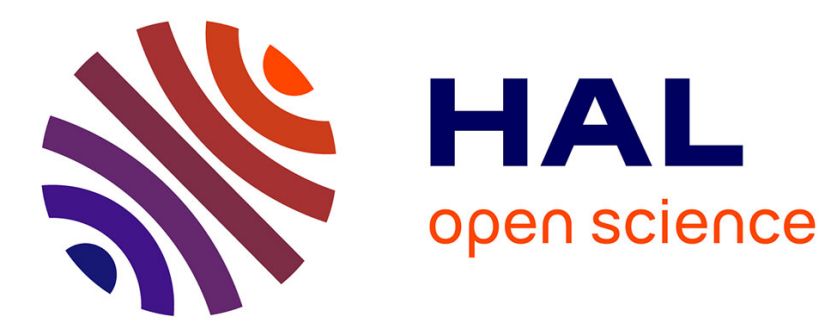

\title{
Lidar measurements of atmospheric lithium
}

Jean-Pierre Jegou, Marie-Lise Chanin, Gérard Mégie, Jacques-Emile Blamont

\section{To cite this version:}

Jean-Pierre Jegou, Marie-Lise Chanin, Gérard Mégie, Jacques-Emile Blamont. Lidar measurements of atmospheric lithium. Geophysical Research Letters, 1980, 7 (11), pp.995-998. 10.1029/GL007i011p00995 . insu-03112000

\section{HAL Id: insu-03112000 \\ https://hal-insu.archives-ouvertes.fr/insu-03112000}

Submitted on 16 Jan 2021

HAL is a multi-disciplinary open access archive for the deposit and dissemination of scientific research documents, whether they are published or not. The documents may come from teaching and research institutions in France or abroad, or from public or private research centers.
L'archive ouverte pluridisciplinaire HAL, est destinée au dépôt et à la diffusion de documents scientifiques de niveau recherche, publiés ou non, émanant des établissements d'enseignement et de recherche français ou étrangers, des laboratoires publics ou privés. 


\title{
LIDAR MEASUREMENTS OF ATMOSPHERIC LITHIUM
}

\author{
Jean-Pierre Jegou, Marie-Lise Chanin, Gérard Mégie, Jacques E. Blamont
}

Service d'Aéronomie du CNRS, 91370 Verrières-1e-Buisson, France.

Abstract. The Haute-Provence Observatory $\left(44^{\circ}\right.$ $\left.\mathrm{N}, 6^{\circ} \mathrm{E}\right)$ lidar facility has been extended to study the atmospheric lithium and its isotopic ratio $\mathrm{Li}^{7} / \mathrm{Li}^{6}$ in the upper atmosphere. The experimental features have been improved in order to lower the detection limit to $3.105 \mathrm{~cm}^{-2}$ for the total abundance with a resolution of $1.2 \mathrm{~km}$ in the altitude profile. The night-time measurements have been carried out from November 1977 to December 1979 and show some characteristic trends.

The seasonal variation of the total abundance is similar to the one observed for sodium. The altitude profile is variable during the night. Total abundance fluctuations and peaks with small scale heights $(1.5 \mathrm{~km})$ are observed on numerous occasions. The layer is sensitive to high-altitude artificial releases, like CAMEO in November 1978 , and to impinging meteor showers. It is concluded that study of the behavior of atmospheric lithium and sodium should further our understanding of the alkali-metals chemistry.

\section{Introduction}

The preliminary photometric measurements of 1ithium total abundance were successfully performed in 1957 by Delannoy and Weill (1958) and the results confirmed by Sullivan and Hunten (1962), Gault and Rundle (1969). Lithium has been shown to be layered around $90 \mathrm{~km}$ as the other alkali metals sodium and potassium. The width of this layer has been estimated to be about $20 \mathrm{~km}$. The vertical total abundance usually observed was of the order of $10^{6} \mathrm{~cm}^{-2}$, whereas abundances of $4.10^{6} \mathrm{~cm}^{-2}$ were reached mainly in fall and winter and, values larger than $10^{7} \mathrm{~cm}^{-2}$ measured sporadicaliy. About fifty percent of these exceptional values were correlated with lithium releases from rocket experiments or thermonuclear explosions (Silverman 1962, Sullivan 1970, Sullivan 1976). Explanations provided up to now for the other fifty percent including meteor showers occurrence have not been quite satisfactory (Gault and Rundle, 1969).

We report in this paper the first lidar measurements of the atmospheric lithium in the atmosphere. As compared to photometric measurements the lidar technique possesses unique experimental features :

- altitude resolution leading to an altitude profile of the number density

\footnotetext{
$\overline{1_{\text {Supplement }}}$ (Table 1) is available with entire article on microfiche. Order from American Geophysical Union, 2000 Florida Ave., N.W., Washington, D.C. 20009. Document L80-003; $\$ 1.00$. Payment must accompany order.
}

Copyright 1980 by the American Geophysical Union.
- nocturnal total abundance average free from twilight conditions

- time resolution leading to the variation of the total abundance during the night

It is also a powerful tool to describe the structure and the intensity of a temporary source like a meteor shower (Mégie et a1., 1978) and the nocturnal variation of sodium number density with high-resolution altitude profiles (Rowlett et al. 1978, Clemesha et al. 1978).

The total abundance of the lithium 7 isotope is three orders of magnitude lower than the sodium and the total abundance of the lithium 6 isotope is still an order of magnitude lower. For this reason, during the two years of obse:vation, the isotopic ratio has only been measured twice, after exceptional enhancements due to artificial releases. Once the experimental improvement was achieved, one of the scientific aims of the 1ithium experiment was to measure the isotopic ratio in meteor showers in order to obtain the cosmological isotopic ratio. The lithium 7 lidar results presented in this paper should contribute to our knowledge of chemical and dynamic interactions of alkali metals with the atmosphere.

\section{Experimental set up}

The ground-based lidar facility set up at the Haute-Provence Observatory $\left(44^{\circ} \mathrm{N}\right.$, France) and used for the study of alkali metals is described in Mégie et a1. (1977). The laser emitter and the photodetector are adapted to the lithium experiment and their characteristics, together with the spectroscopic data of the lithium atom, are presented in Table 1. An important addition to the earlier system is a servo-wavelength control ensuring the spectral stability of the laser and the ability to automatically tune from one isotope resonance line to the other. Its description will be presented in detail in a future publication (Cahen et al., 1980). The backscattered signal is received on a $80 \mathrm{~cm}$ Cassegrain telescope, detected by a photomultiplier and, after amplification and discrimination, fed into a 220 channel photon counting system.

The number $S_{0}$ of the received photons backscattered between the altitude $z$ and $z+\Delta z$ is for a single shot :

$$
S_{0}=T \cdot \frac{A}{z} 2 \cdot \bar{n} \cdot \Delta z \cdot \sigma_{e} \cdot\left(\frac{E_{o}}{h_{v}}\right)
$$

where

- T is the global efficiency of the lidar system (optics and atmospheric transmission, quantum efficiency of the photomultiplier, ...)

- A is the telescope area

$-\bar{n}$ is the mean number density between $z$ and $z+$ $\Delta z$

- hv is the individual photon energy at the frequency $\nu$.

- $\sigma_{e}$ is the integrated effective cross-section 
defined as the product of the laser line profile by the resonance line profile.

- $E_{0}$ is the laser energy per pulse (see Table 1). The signal to noise ratio for $X$ shots is given, assuming Poisson statistics for the received signals, by :

$$
R=\sqrt{X} \cdot \frac{S_{Q}}{\sqrt{S_{O}+B_{0}}}
$$

where $B_{0}^{-}$is the photo-electronic background due to the brightness of the sky and the PMT dark noise in the range bin $\Delta z$.

Thus, if $\mathrm{S}_{O} \gg \mathrm{B}_{0}, R$ is proportional to $\sqrt{\mathrm{X} . \mathrm{E}_{\mathrm{O}}}$ whereas if $S_{O} \ll B_{O}$, for a faint signal, $R$ is proportional tol $\sqrt{\mathrm{X}}$. $\mathrm{E}_{\mathrm{O}}$.

In the case of lithium measurements, the received signal is small due to the low total abundance of scatterers ( $10^{6} \mathrm{~atm} . \mathrm{cm}^{-2}$ ); and thus, the signal to noise ratio has to be enhanced by maximizing $E_{O}$ and reducing $B_{O}$.

A larger value of $E_{O}$ is obtained by using a flash-lamp pumped dye laser with high energy per pulse $(800 \mathrm{~mJ})$ and low repetition rate $(2 \mathrm{~Hz}) \mathrm{ra}-$ ther than a high repetition rate and low energy per pulse as obtained with a laser-pumped dye laser.

Two processes have been used to reduce the noise $\mathrm{B}_{\mathrm{O}}$ :

- a thermo-tlectric cooling system for the photomultiplier to reduce the value of the dark current to 10 counts per sec.

- a small receiving field of view $\left(\leqslant 5.10^{-4} \mathrm{rd}\right)$ compatible with the laser divergence to reduce the nocturnal sky background to 30 counts per sec.

Taking into account these experimental features the detection limit of total abundance is $3.10^{5} \mathrm{~cm}^{-2}$.

The uncertainties in the lithium measurements are of two different kinds :

- a relative error on the altitude profile strictly relevant to the Poisson statistics law for the signal and thus dependent upon the integration time and the altitude resolution.

- an absolute error on the number density or total abundance value mainly due to the calibration using the atmospheric density profile as measured by Rayleigh scattering at lower altitudes, and to the efficiency of the resonant excitation $\left(\sigma_{e}\right)$. The uncertainty on the effective cross-section $\sigma_{e}$ is reduced by using the servo-wavelength control ensuring the wavelength stability and measuring the lines shape and the energy fluctuations for each shot. The spectral stability of the laser is certain to be better than a tenth of the laser linewidth which implies the knowledge of $\sigma_{e}$ within $3 \%$.

The calibration of the atmospheric density requires the choice of a reliable density model in the $40 \mathrm{~km}$ range taking into account the shortterm and seasonal variations. Checks are made to ensure that the signal variation over the range $30-50 \mathrm{~km}$ is consistent with the value deduced from the appropriate model atmosphere (US Standard 1976). Taking into account these different sources of uncertainties and for the typical experimental conditions described in Table 1 , and assuming a one-hour integration time ( 7200 shots), an altitude resolution of $1.2 \mathrm{~km}$ and a lithium total abundance of $1.5 .10^{6} \mathrm{~cm}^{-2}$ for a $20 \mathrm{~km} \mathrm{ex}-$ tent of the layer, the relative error on the altitude profile is of the order of $\pm 20 \%$ and the absolute error on the total abundance is $\pm 20 \%$.

\section{Results and discussion}

The night-time lidar measurements of atmospheric lithium reported here have been carried out from November 1977 to December 1979. The detection limit has appeared low enough to study the seasonal variation of the lithium 7 isotope total abundance, but the lithium 6 isotope detection, and then the measurement of the isotopic ratio, have only been possible in the case of exceptional events such as (see fig. ${ }^{-1}$ ) :

- the CAMEO lithium release from Nimbus 7 (November 6,7 and 8,1978 )

- a sporadic enhancement between April 21 and 25 , 1979 following two artificial releases from Poker Flat (Alaska) on April 15 and $18,1979$.

The isotopic ratio was for those two cases 11.2 on November 7 and on April 22, with an accuracy of $20 \%$ due to the fast switching between the 2 resonance lines $\left(2 \mathrm{mn}^{-1}\right)$ avoiding the need

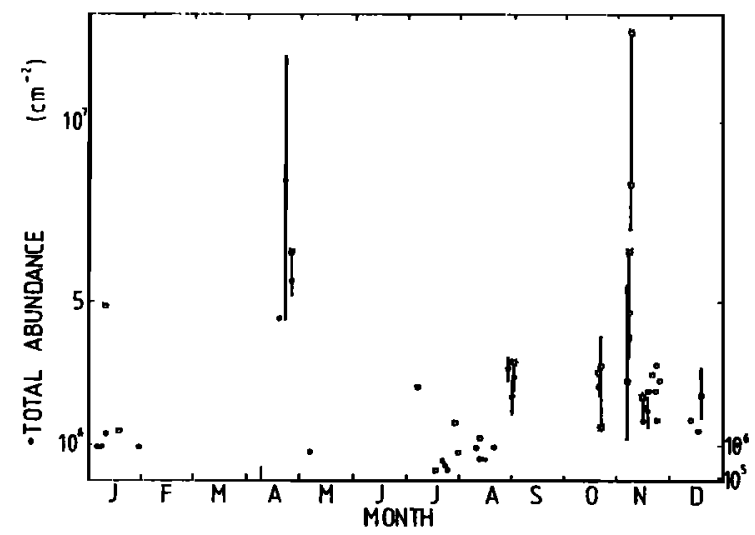

Fig. 1 : Data averaged from the measurements during the night for different years ( $\circ$ 1977, $\square$ 1978, $\bullet 1979$ ) and data obtained close to sunrise ( $\not x)$ and sunset ( $\not$ ) are identified on the chart. A vertical arrow is an indication of the nocturnal variation. 


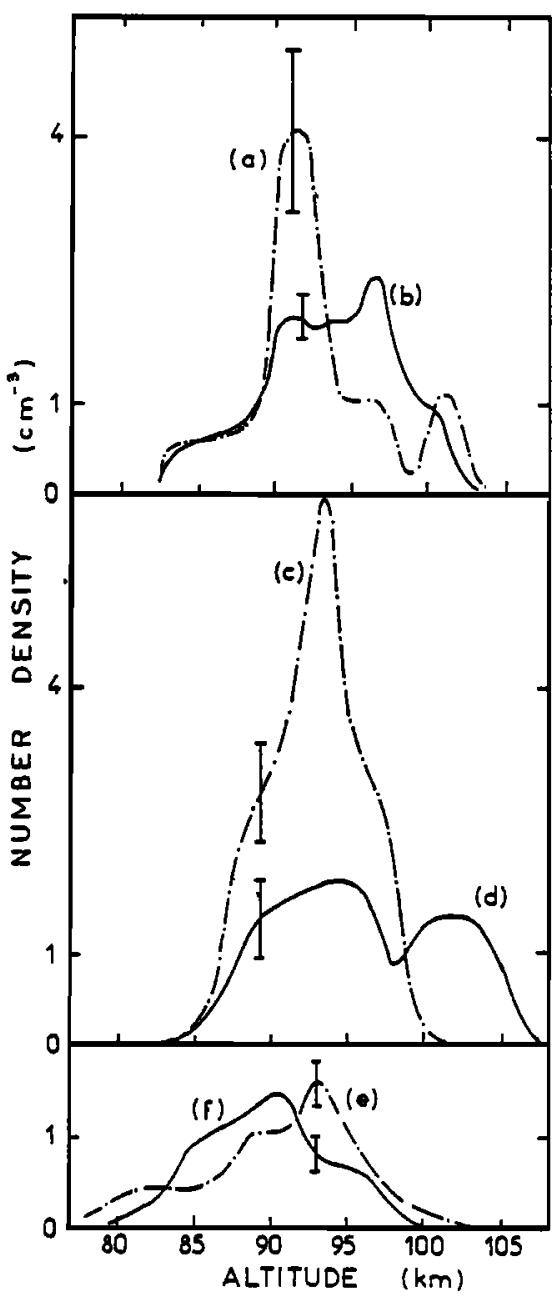

Fig. 2 : Typical fall and winter altitude profiles for 3 nights :

- September 1, $1979:$ (a) average between 21 : 30 and 22 : 30 UT

(b) average over the night.

- October 21, 1978 : (c) average between $21: 00$ and $23: 00 \mathrm{UT}$

(d) average betwwen $00: 00$ and $02: 00 \mathrm{UT}$

- November 15, 1979 : hourly average

(e) for $22: 00 \mathrm{UT}$

(f) for $02: 00 \mathrm{UT}$

for Rayleigh calibration. Recent improvements in the experimental performances allow measurements of the isotopic ratio with the same accuracy whenever the lithium 7 total abundance is around $2.10^{6} \mathrm{~cm}^{-2}$, as usually is the case in winter.

During thesefirst two years of observation, we were mainly concerned with the study of the 1ithium 7 seasonal variation. The two exceptional events mentioned above should not be considered in that study; the time constant of disappearance of the lithium produced during those sporatic events appears to be of the order of a few days, and it seems reasonable to consider that such inputs should not affect the seasonal variation observed.

As shown in fig. 1, the fall and winter averaged total abundance appears to be larger than the summer one by a factor of 5, indicating that the lithium seasonal behavior is very close to the sodium one.

Typical altitude profiles are displayed in fig. 2 and 3 . They show a large variability in the shape of the layer but some general trends can be deduced from the data.

The fall (or winter) profiles of lithium are most of the time coarsely located arcund $92 \mathrm{~km}$, higher than sodium by about $4 \mathrm{~km}$. As a general feature, when the total abundance is large during fall ( 1.5 to $3.10^{6} \mathrm{~cm}^{-2}$ ) the altitude profile peaks with small scale heights on both sides and varies in altitude. A typical sharp profile averaged over one hour and the profile averaged over the same whole night are presented in fig. $2 a$ and 2b. The thin layer, shifting during the night, is responsible for the small scale heights and the appearance of a plateau-type shape in fig. $2 \mathrm{~b}$. This points out the importance of temporal resolution in the measurements of such layered structure.

In fig. 2c and 2d, we notice a rather sharp layer at the beginning of the night and a decreasing total abundance during the night. On September 1 , 1979, (fig. $2 a$ and $2 b$ ), the total abundance remains constant within $20 \%$. On the other hand, a decrease by a factor of 4 of the central part of the layer is observed on October 21, 1978 ( $\mathrm{fig}$. $2 \mathrm{c}$ and $2 \mathrm{~d}$ ) even though this period is situated in the middle of the Orionids shower (October 18 to 26), with meteorites of fast velocity $\left(66 \mathrm{~km} \mathrm{~s}^{-?}\right)$, which may be responsible for the localized input around $100 \mathrm{~km}$. A changing structure with a total abundance stable within $10 \%$ has been observed on November 15, 1979. Two samples of the hourly average profiles are shown in fig. $2 e$ and $2 f$ and, from the total set of data during that night, we

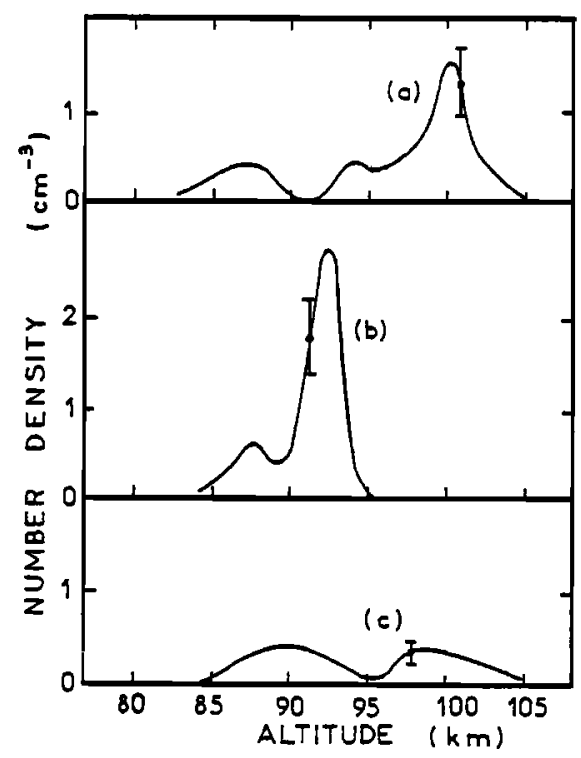

Fig. 3 : Typical summer altitude profiles averaged over several nights

(a) on August 11 and 12, 1979

(b) on August 21 and 22, 1979.

(c) from Ju1y 21 to July 23, 1979. 
can observe a descending layer with a maximum around $93 \mathrm{~km}$ at $23 \mathrm{~h} \mathrm{U}$.T. and around $89 \mathrm{~km}$ at $4 \mathrm{~h}$ U.T. emphasizing the importance of the dynamics as already observed with sodium. A plateau-type structure is obtained for the profils averaged over the whole night. This shape is obtained most of the time for the winter profiles averaged over the night.

In summer, due to the smaller total abundance and shorter night duration the measurements have to be averaged over more than one night. But even with this long integration time, a great variability of the altitude profiles is clearly observed as shown in fig. 3. Fig. 3a shows the impinging Perseids meteor shower on August 11/12, 1979 taking place at the same altitude as the Orionids input. The profile in fig. $3 \mathrm{~b}$, on August 21/22, has lost all memory of the altitude of the impact and tends to an autumnal profile. In fig. $3 \mathrm{c}$ is presented a typical profile for the smallest total abundances encountered but, because of this low value and the lack of experiments from May till June, this structure should be confirmed before being considered as characteristic of the summer profile.

\section{Conclusion}

The first lidar measurements of atmospheric lithium are consistent with former photometric measurements of the total abundance but show a much more detailed altitude profile.

The total abundance is very sensitive to spurious enhancements due to rocket releases and the long term reaction (several years) of such inputs is not well defined (Gadsden 1970). Ignoring these exceptional values, the general behavior of lithium total abundance shows a seasonal variation similar to the one observed for sodium (Mégie and Blamont, 1977). A dynamic nocturnal a1titude profile, with or without a total abundance variation, appears to be a common characteristic of all the lithium measurements. The altitude range of the layer is more stable in fall and winter than in summer. Iike the other alkali metals, the lithium altitude profile and total abundance are sensitive to impinging meteor showers (Mégie et al., 1978), but the consequent enhancement and altitude profile evolution are not much larger than typical nocturnal variation. In this respect, a strong and reversible sink and/or source process, involving cluster ions, could be envisaged. We have pointed out the control of the lithium layer by meteor showers, chemistry and/or dynamics.

Experiments on lithium will now be performed simultaneously with sodium measurements in order to provide data for a more accurate analysis of alkali metals chemistry and dynamics on a timescale less than one hour.

\section{Acknowledgements}

We wish to thank Charles Fehrenbach, the Director of the Haute-Provence Observatory, for his hospitality. We are grateful to J.P. Schneider and F. Syda who helped to collect the data. This program was supported by the CNRS and INAG.

\section{Keferences}

Cahen, C., P. Gildwarg, J.P. Jegou, J. Porteneuve Servo-wavelength control device for lidar experiment, to be submitted to J. Appl. Physics, 1980. Clemesha, B.R., V.W. J.H. Kirchhoff, D.M. Simonich and $H$. Takahashi, Evidence for an extra-terrestrial source for the mesospheric sodium layer, Geophys. Res. Letters, 5, 873-876, 1978.

Delannoy, J., G. Weil1, Observation d'une nouvelle raie d'émission crépusculaire atmosphérique, C.R. Acad. Sci. Paris 247, 806-807, 1958.

Gadsden, M., Metallic atoms and ions in the upper atmosphere, Ann. Geophys. 26, 141-150, 1970.

Gault, W.A., H.N. Rundle, Twilight observations of upper atmospheric sodium, potassium an lithium Can. J. Phys. 47, 85, 1969.

Mégie, G., F. Bos, J.E. Blamont, M.L. Chanin, Simultaneous nighttime lidar measurements of atmospheric sodium and potassium, Planet. Space Sci $26,27-35,1978$.

Mégie, G., J.E. Blamont, Laser sounding of atmospheric sodium : interpretation in terms of global atmospheric parameters, Planet. Space Sci: 25, 1093-1109, 1977.

Rowlett, J.R., C.S. Gardner, E.S. Richter, C.F. Sechrist Jr., Lidar observation of wave-like structure in the atmospheric sodium layer, Geophys. Res. Letters, 5, 683-686, 1978.

Silverman, S.M., Comments on lithium in the upper atmosphere, Planet. Space Sci. 9, 89-92 (1962).

Sullivan, H.M., D.M. Hunten, Lithium twilight at Saskatoon, 1960-61, Nature 193, 1064-1065,1962. Sullivan, H.M., Some unusual red twilight emissions, Ann. Geophys. 26, 161-166, 1970.

Sullivan, H.M., Vertical distribution of atomic lithium in the upper atmosphere following a rocket release, Ann. Geophys. 32, 13-21, 1976.

Sullivan,H.M., Enhancement of twilight 1ithium emission following a rocket release, Ann. Geophvs. $32,407-409,1976$.

(Received March 14, 1980; accepted May 16, 1980.) 